\title{
Antioxidant, Anti-acetylcholinesterase and Composition of Biochemical Components of Russian Deer Velvet Antler Extracts
}

\author{
Jae-Young Je, Pyo-Jam Park', Dong Hwan Lim², Byong-Tae Jeon ${ }^{3}$, Kang Hee Kho ${ }^{4}$, and Chang-Bum Ahn* \\ School of Food Technology and Nutrition, Chonnam National University, Yeosu 550-749, Korea \\ ${ }^{1}$ Department of Biotechnology, Konkuk University, Chungju 380-701, Korea \\ ${ }^{2}$ Shin Hung Pharm. Co., Yeosu, 550-230, Korea \\ ${ }^{3}$ Korea Nokyong Research Center, Konkuk University, Chungju 380-701, Korea \\ ${ }^{4}$ Department of Aquatic Biology, Chonnam National University, Yeosu 550-749, Korea
}

\begin{abstract}
Russian deer velvet antlers were divided into three parts and subjected to a extraction process using hot water at 100, 110, and $120^{\circ} \mathrm{C}$ or an extraction with $70 \%$ ethanol. Each extract was analyzed for its biochemical components, including uronic acid, sulfated-glycosaminoglycans (sulfated-GAGs), and sialic acid, and the antioxidant and anti-acetylcholinesterase activities were investigated. Different levels of uronic acid and sulfated-GAGs were observed in the extracts according to the water temperature used for the extraction, and contents decreased with increasing extraction temperature. The upper layer of each extract showed high amounts of uronic acid and sulfated-GAGs, followed by the middle and base layers. Ethanol extraction was more effective for recovering uronic acid than sulfated-GAGs. Sialic acid content was the highest in the $110^{\circ} \mathrm{C}$ extracts but was not observed in the ethanol extracts. Velvet antler extracts showed strong antioxidant activities against DPPH and hydrogen peroxide as well as strong reducing power in a dose-dependent manner. However, the antioxidant activities were different in each layer and according to the extraction method. Additionally, velvet antler extracts exhibited inhibitory activity against acetylcholinesterase, which is associated with Alzheimer's disease, in a dose-dependent manner. These results suggest that velvet antler extracts are useful as a functional food ingredient and/or a pharmaceutical.
\end{abstract}

Key words: velvet antler, uronic acid, sulfated-glycosaminoglycans, sialic acid, antioxidant activity, anti-acetylcholinesterase

\section{Introduction}

Overproduction of free radicals and reactive oxygen species (ROS) is believed to be associated with cellular and tissue pathogenesis, which leads to several chronic diseases such as cancer, diabetes mellitus, and neurodegenerative and inflammatory diseases (Butterfield et al., 2002; Pryor and Ahn, 1982). It is also believed that ROS can oxidize biomacromolecules such as DNA, proteins, membrane lipids, and vital molecules. To prevent or slow down the oxidative stress induced by ROS, supplementation of antioxidants may be useful. Therefore, great interest has been focused on the development of natural antioxidants that are safe, non-toxic, and effective.

Acetylcholinesterase (AChE) is an oligomeric enzyme

\footnotetext{
*Corresponding author: Chang-Bum Ahn, School of Food Technology and Nutrition, Chonnam National University, Yeosu 550-749, Korea. Tel: 82-61-659-7411; Fax: 82-61-6597419; E-mail: a321@chonnam.ac.kr
}

that attaches to the neuromuscular junction, which catalyzes the cleavage of neurotransmitter acetylcholine to choline and acetate. Based on the cholinergic hypothesis, loss of cholinergic function due to a deficiency in neurotransmitter acetylcholine is the only evidential finding responsible for the cognitive characteristics of Alzheimer's disease (AD). Therefore, AChE inhibitors are widely used in AD patients to inhibit AChE activity, thereby activating the central cholinergic system and alleviating cognitive deficits.

In Korea, unossified horn of Cervus elaphus (Cervidae) is generally referred to as 'Nokyong' and is one of the most popular Korean traditional medicines, the benefits of which are supported by extensive in vivo and in vitro studies (Kim, 1994; Suttie et al., 1994). Recently, the beneficial effects of $C$. elaphus with regard to its antiinflammatory, anti-stress, anti-aging, and antioxidant activities were studied (Je et al., 2010; Sunwoo et al., 1997; Takikawa et al., 1972; Wang et al., 1988a; Wang et al., 1988b; Zhang et al., 1992). In our previous report, we 
reported the contents of biologically active materials such as uronic acid, sulfated-glycosaminoglycans (sulfatedGAGs), and sialic acid in New Zealand deer velvet antler extracts under various conditions as well as their antioxidant effects on various model systems (Je et al., 2010). These compounds are generally considered for quality evaluation of velvet antler, and in particular, sulfated-glycosaminoglycans had been shown to reduce pain in osteoarthritis patients (Paroli et al., 1991). However, there is very little information on Russian deer velvet antler in this regard.

In this study, Russian deer velvet antler was divided into three parts, which were then subjected to extraction using hot water at three different temperatures and also $70 \%$ ethanol solution. The biochemical compositions of the extracts were analyzed, and their antioxidant and antiacetylcholinesterase activities were evaluated.

\section{Materials and Methods}

\section{Chemicals}

All chemicals, including 2,2-diphenyl-1-picrylhydrazyl (DPPH), ethylenediaminetetraacetic acid (EDTA), FolinCiocalteu's phenol reagent, hydrogen peroxide, 2,2-azinobis(3-ethylbenzthiazoline)-6-sulfonic acid (ABTS), acetylcholinesterase (electric eel), acetylthiocholine, galacturonic acid, carbazole, 1,9-dimethylmethylene blue, chondroitin 4-sulfate, $\mathrm{N}$-acetylneuraminic acid, periodic acid, peroxidase, and potassium ferricyanide, were purchased from Sigma Chemical Co. (USA). Other chemicals and reagents used were of analytical grade.

\section{Preparation of velvet antler extracts}

Russian red deer velvet antler (C. elaphus) was donated by Shin Hung Pharm. Co. (Yeosu, Korea). The antler was divided into three parts (upper (RU), middle (RM), and base part (RB)), with a $60 \mathrm{~g}$ portion being used for each experiment (Fig. 1). The first extraction process was conducted with hot water at $100^{\circ} \mathrm{C}$ for $1 \mathrm{~h}$ by autoclaving (MAC-601, Tokyo Rikakikai Co., Ltd., Japan) (designated as RU100, RM100, and RB100). After filtration, the residue was subjected to re-extraction at $110^{\circ} \mathrm{C}$ for $1 \mathrm{~h}$, followed by filtration (designated as RU110, RM110, and RB110). Finally, the residue from the extraction at $110^{\circ} \mathrm{C}$ was subjected to re-extraction at $120^{\circ} \mathrm{C}$ for $2 \mathrm{~h}$, repeated twice, and the supernatant was collected by filtering (RU120, RM120, and RB120). The justification for this is that water at $100^{\circ} \mathrm{C}$ may not be hot enough to completely extract all of the functional components. A $60 \mathrm{~g}$

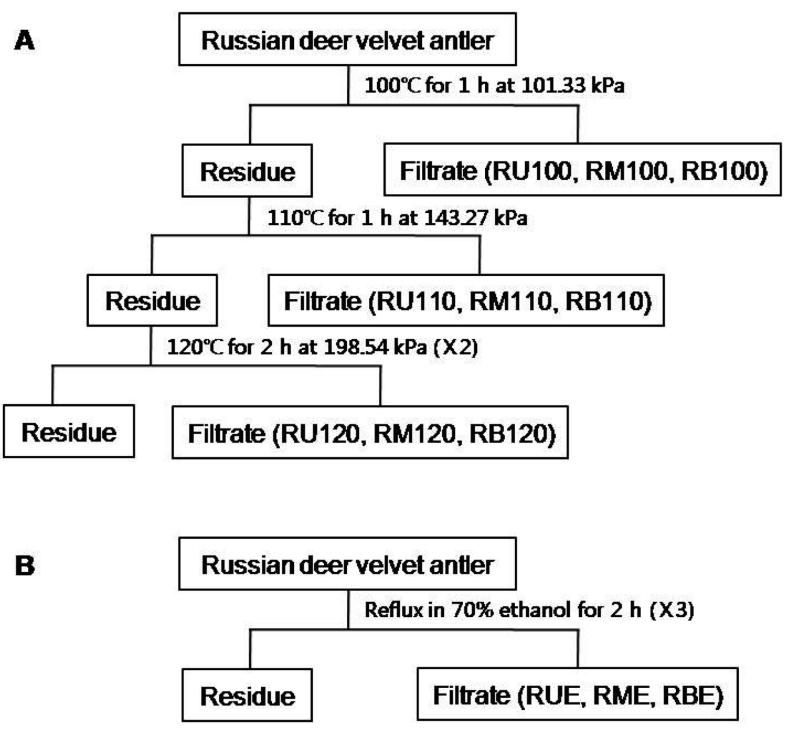

Fig. 1. Schematic diagram for the extraction of Russian deer velvet antler. (A), water extraction; (B), 70\% ethanol extraction.

portion of the antler was also subjected to extraction using $70 \%$ ethanol solution for $2 \mathrm{~h}$, which was repeated three times (designated as RUE, RME, and RBE). All recovered extracts were lyophilized on a freeze dryer (FD8508, Ilshin Co., Ltd., Korea) for $5 \mathrm{~d}$.

\section{Analysis of uronic acid, sulfated-GAGs, and silalic acid contents}

Uronic acid content was determined by the carbazole reaction. Briefly, a $50 \mu \mathrm{L}$ serial dilution of standard or sample was placed in a 96-well plate, after which a 200 $\mu \mathrm{L}$ solution of $25 \mathrm{mM}$ sodium tetraborate in sulfuric acid was added. The plate was heated for $10 \mathrm{~min}$ at $100^{\circ} \mathrm{C}$ in an oven. After cooling at room temperature for $15 \mathrm{~min}$, $50 \mu \mathrm{L}$ of $0.125 \%$ carbazole in absolute ethanol was carefully added. After heating at $100^{\circ} \mathrm{C}$ for $10 \mathrm{~min}$ in an oven and cooling at room temperature for $15 \mathrm{~min}$, the plate was read using a microplate reader (ELx $808^{\mathrm{TM}}$, BioTek, VT, USA) at a wavelength of $550 \mathrm{~nm}$ (Cesaretti et al., 2003).

Sulfated-GAGs content was determined by the dimethylmethylene blue (DMB) dye binding method (Farndale et al., 1986). Briefly, the color reagent was prepared by dissolving $0.008 \mathrm{~g}$ of DMB in a solution containing 1.185 $\mathrm{g}$ of $\mathrm{NaCl}, 1.520 \mathrm{~g}$ of glycine, $0.47 \mathrm{~mL}$ of $\mathrm{HCl}(12 \mathrm{M})$, and $500 \mathrm{~mL}$ of distilled water. Each sample was mixed with $1 \mathrm{~mL}$ of color reagent, and the absorbance was read immediately at $525 \mathrm{~nm}$.

Sialic acid content was determined by the method of Warren (1959) with slight modification. Briefly, samples were hydrolyzed in $0.1 \mathrm{~N} \mathrm{H}_{2} \mathrm{SO}_{4}$ in a final volume of 1.0 
$\mathrm{mL}$ for $1 \mathrm{~h}$ at $80^{\circ} \mathrm{C}$. Both standard and sample were incubated with $1 \mathrm{~mL}$ of periodate solution at $37^{\circ} \mathrm{C}$ for $30 \mathrm{~min}$. After addition of $0.25 \mathrm{~mL}$ of sodium thiosulfate $(0.32 \mathrm{M})$, the tubes are shaken until the yellow-brown color disappeared. The reaction was completed by the addition of $1.25 \mathrm{~mL}$ of thiobarbituric acid $(0.1 \mathrm{M})$, after which the tubes were heated at $100^{\circ} \mathrm{C}$ for $15 \mathrm{~min}$ and cooled to room temperature. The product was extracted with acidic butanol, and optical density was determined at $549 \mathrm{~nm}$.

\section{Assay for antioxidant activity}

DPPH scavenging activity was measured according to the method of Blois (1958). DPPH solution $\left(1.5 \times 10^{-4} \mathrm{M}\right.$, $100 \mu \mathrm{L})$ was mixed with and without each extract $(100$ $\mu \mathrm{L}$ ), after which the mixture was incubated at room temperature for $30 \mathrm{~min}$. After standing for $30 \mathrm{~min}$, absorbance was recorded at $517 \mathrm{~nm}$ using a microplate reader.

Hydrogen peroxide scavenging activity was determined according to the method of Müller (1985). Briefly, 100 $\mu \mathrm{L}$ of $0.1 \mathrm{M}$ phosphate buffer ( $\mathrm{pH} 5.0$ ) was mixed with each extract in a 96-well plate. Then, $20 \mu \mathrm{L}$ of hydrogen peroxide was added to the mixture, followed by incubation at $37^{\circ} \mathrm{C}$ for $5 \mathrm{~min}$. After the incubation, $30 \mu \mathrm{L}$ of 1.25 $\mathrm{mM}$ ABTS and $30 \mu \mathrm{L}$ of peroxidase ( 1 unit $/ \mathrm{mL}$ ) were added to the mixture, followed by incubation at $37^{\circ} \mathrm{C}$ for $10 \mathrm{~min}$. The absorbance was recorded at $405 \mathrm{~nm}$ using a microplate reader.

The reducing power was determined according to the method of Oyaizu (1986). Each of the extracts was mixed with $0.5 \mathrm{~mL}$ of $0.2 \mathrm{M}$ phosphate buffer $(\mathrm{pH} 6.6)$ and 0.5 $\mathrm{mL}$ of potassium ferricyanide $(1 \%)$. The mixture was then incubated at $50^{\circ} \mathrm{C}$ for $20 \mathrm{~min}$, followed by addition of $0.5 \mathrm{~mL}$ of TCA $(10 \%)$ to the mixture and centrifugation at $1,036 \mathrm{~g}$ for $10 \mathrm{~min}$. From the upper layer of the solution, $0.5 \mathrm{~mL}$ of solution was mixed with $0.5 \mathrm{~mL}$ of distilled water and $0.1 \mathrm{~mL}$ of $\mathrm{FeCl}_{3}(0.1 \%)$, and the absorbance was measured at $700 \mathrm{~nm}$. Increased absorbance of the reaction mixture indicated increased reducing power.

\section{Assay for inhibition of acetylcholinesterase}

Acetylcholinesterase inhibition assay was conducted via the spectrophotometric method developed by Ellman et al. (1961) with slight modification. Acetylthiocholine chloride was employed as the substrate to assay for inhibition of acetylcholinesterase. The reaction mixture contained $140 \mu \mathrm{L}$ of $100 \mathrm{mM}$ sodium phosphate buffer $(\mathrm{pH}$ 8.0), $20 \mu \mathrm{L}$ of test sample solution, and $20 \mu \mathrm{L}$ of acetylcholinesterase $(0.36 \mathrm{U} / \mathrm{mL})$, which were mixed and incubated for $15 \mathrm{~min}$ at room temperature. The reactions were then initiated via the addition of $10 \mu \mathrm{L}$ of 5-5'-thiobis-2nitrobenzoic acid $(0.5 \mathrm{mM})$ and $10 \mu \mathrm{L}$ of acetylthiocholine chloride $(0.6 \mathrm{mM})$. Hydrolysis of acetylthiocholine chloride was monitored at $412 \mathrm{~nm}$ for $15 \mathrm{~min}$ based on the formation of yellow 5-thio-2-nitrobenzoate anion, which resulted from the reaction of 5-5'-thiobis-2-nitrobenzoic acid with thiocholine, by the enzymatic hydrolysis of acetylthiocholine chloride.

\section{Statistical analysis}

Data were evaluated for statistical significance using the SPSS package for Windows (Version 14.0). Values were expressed as mean \pm standard error (SE). The mean values were compared using one-way ANOVA followed by Duncan's test. $p$-value of less than 0.05 was considered significant.

\section{Results}

Biochemical components such as uronic acid, sulfatedGAGs, and sialic acid were analyzed in each extract, and the results are shown in Table 1. Uronic acid contents of the hot water extracts significantly decreased with increasing temperature $(p<0.05)$, and the extract obtained from the upper part possessed significantly higher uronic acid content than those of the extracts obtained from the middle and base parts. On the other hand, the uronic acid contents in each part of the $70 \%$ ethanol extracts were significantly higher than those of the hot water extracts. Further, uronic acid content was the highest in the upper part, followed by the middle and base parts. SulfatedGAGs contents of each hot water extract decreased with increasing temperature, and the extract obtained from the upper part showed a higher level of sulfated-GAGs than those of the extracts obtained from the middle and base parts. No significant difference was observed between the extracts from the middle and base parts. Furthermore, $70 \%$ ethanol extracts of each part showed lower sulfatedGAGs contents compared to those of the hot water extracts. Sialic acid contents of each hot water extract showed a different pattern compared to the contents of uronic acid and sulfated-GAGs. Overall, sialic acid content was highest in the upper part, and extracts at $110^{\circ} \mathrm{C}$ showed the highest content. However, no sialic acid was observed in the $70 \%$ ethanol extracts.

Antioxidant activities of Russian deer velvet antler extracts were evaluated based on scavenging of DPPH, hydrogen peroxide, and reducing power. As shown in Fig. 2, velvet antler extracts obtained from each part 
Table 1. Uronic acid, sulfated-GAGs, and sialic acid contents of Russian deer velvet antler extracts

\begin{tabular}{|c|c|c|c|c|c|}
\hline \multirow{2}{*}{\multicolumn{2}{|c|}{ Extracts }} & \multicolumn{4}{|c|}{ Contents $(\mu \mathrm{g} / \mathrm{mg})$} \\
\hline & & $100^{\circ} \mathrm{C}$ water & $110^{\circ} \mathrm{C}$ water & $120^{\circ} \mathrm{C}$ water & $70 \%$ ethanol \\
\hline \multirow{3}{*}{ Upper part } & Uronic acid & $59.72 \pm 1.44^{\mathrm{a}}$ & $43.62 \pm 0.72^{b}$ & $12.16 \pm 1.56^{\mathrm{c}}$ & $112.34 \pm 1.18^{\mathrm{d}}$ \\
\hline & Sulfated-GAGs & $67.96 \pm 3.20^{\mathrm{a}}$ & $51.20 \pm 3.50^{\mathrm{b}}$ & $38.80 \pm 2.70^{\mathrm{c}}$ & $2.46 \pm 0.60^{\mathrm{d}}$ \\
\hline & Sialic acid & $2.61 \pm 0.12^{\mathrm{a}}$ & $9.07 \pm 0.46^{\mathrm{b}}$ & $5.90 \pm 0.39^{c}$ & ND \\
\hline \multirow{3}{*}{ Middle part } & Uronic acid & $37.29 \pm 1.35^{\mathrm{a}}$ & $27.28 \pm 1.44^{b}$ & $15.15 \pm 1.81^{\mathrm{c}}$ & $106.03 \pm 1.50^{\mathrm{d}}$ \\
\hline & Sulfated-GAGs & $17.12 \pm 2.05^{\mathrm{a}}$ & $15.26 \pm 2.31^{\mathrm{a}}$ & $10.26 \pm 1.50^{\mathrm{b}}$ & $2.83 \pm 0.60^{\mathrm{c}}$ \\
\hline & Sialic acid & $6.02 \pm 0.34^{\mathrm{a}}$ & $6.51 \pm 0.42^{\mathrm{a}}$ & $2.37 \pm 0.31^{\mathrm{b}}$ & ND \\
\hline \multirow{3}{*}{ Base part } & Uronic acid & $33.69 \pm 0.87^{\mathrm{a}}$ & $20.84 \pm 1.29^{b}$ & $10.02 \pm 0.74^{\mathrm{a}}$ & $91.43 \pm 2.01^{\mathrm{d}}$ \\
\hline & Sulfated-GAGs & $18.04 \pm 1.80^{\mathrm{a}}$ & $14.70 \pm 1.90^{\mathrm{b}}$ & $8.76 \pm 1.40^{\mathrm{c}}$ & $2.46 \pm 0.60^{\mathrm{d}}$ \\
\hline & Sialic acid & $4.32 \pm 0.25^{\mathrm{a}}$ & $4.56 \pm 0.38^{\mathrm{a}}$ & $2.61 \pm 0.28^{\mathrm{b}}$ & ND \\
\hline
\end{tabular}

$\overline{\mathrm{a}-\mathrm{d}}$ The values with different superscripts indicate a significant difference $(p<0.05)$.

Values are mean $\pm \operatorname{SE}(n=3)$.

ND: not detected
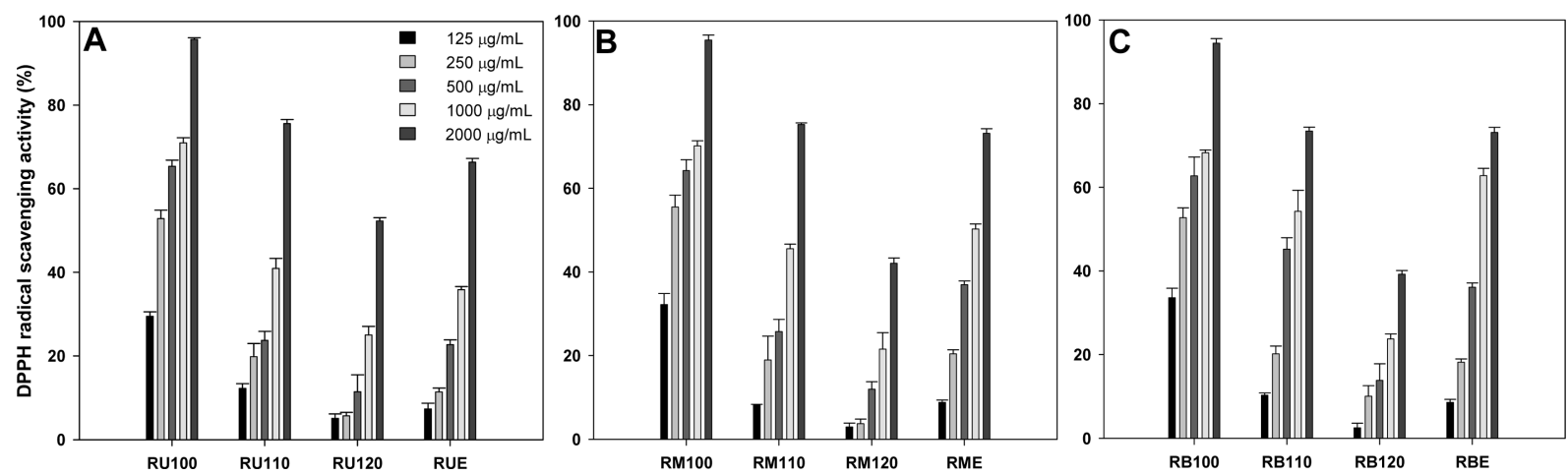

Fig. 2. DPPH radical scavenging activities of Russian deer velvet antler extracts. (A), Upper part extracts with hot water at $100^{\circ} \mathrm{C}$, $110^{\circ} \mathrm{C}$, and $120^{\circ} \mathrm{C}$ and $70 \%$ ethanol; (B), Middle part extracts with hot water at $100^{\circ} \mathrm{C}, 110^{\circ} \mathrm{C}$, and $120^{\circ} \mathrm{C}$ and $70 \%$ ethanol; $(\mathrm{C})$; Base part extracts with hot water at $100^{\circ} \mathrm{C}, 110^{\circ} \mathrm{C}$, and $120^{\circ} \mathrm{C}$ and $70 \%$ ethanol. Results are presented as means $\pm \mathrm{SE}$ of three determinations.

effectively quenched DPPH radical in a dose-dependent manner. The DPPH scavenging activity decreased with increasing temperature, and RU100, RM100, and RB100, which were extracted at $100^{\circ} \mathrm{C}$ from each part, exhibited the highest scavenging activities. The $70 \%$ ethanol RUE, RME, and RBE also showed DPPH radical scavenging activities in a dose-dependent manner, whereas their scavenging activities were lower than those of RU100, RM100, and RB100, respectively. Fig. 3 depicts hydrogen peroxide scavenging activity, which appeared to be augmented at increasing concentrations. All hot water extracts of velvet antler displayed similar activities, whereas the $70 \%$ ethanol extracts showed comparatively higher activity than those of the hot water extracts. The levels of reducing power of the velvet antler extracts are shown in Fig. 4. Dose-dependent augmentation of reducing power was observed, and the $70 \%$ ethanol extracts (RUE, RME, and RBE) showed comparatively higher reducing power compared to those of the hot water extracts. In addition, the upper part extracts (RU100, RU110, and RU120) possessed higher reducing power than those of the middle (RM100, RM110, and RM120) and base part extracts (RB100, RB110, and RB120).

Acetylcholinesterase (AChE) inhibitory activities of velvet antler extracts were investigated using Ellman assay, and the results are depicted in Fig. 5. All of the extracts inhibited AChE activity in a dose-dependent manner, and the extracts at $100^{\circ} \mathrm{C}$ in each part, including RU100, RM100, and RB100, showed potent anti-AChE activities. On the other hand, RUE, RME, and RBE also inhibited $\mathrm{AChE}$ activity, and the levels of inhibition were higher and/or similar compared to those of RU100, RM100, and RB100.

\section{Discussion}

Generally, velvet antler can be divided into four parts, the tip, upper, middle, and base part, and is used to treat 

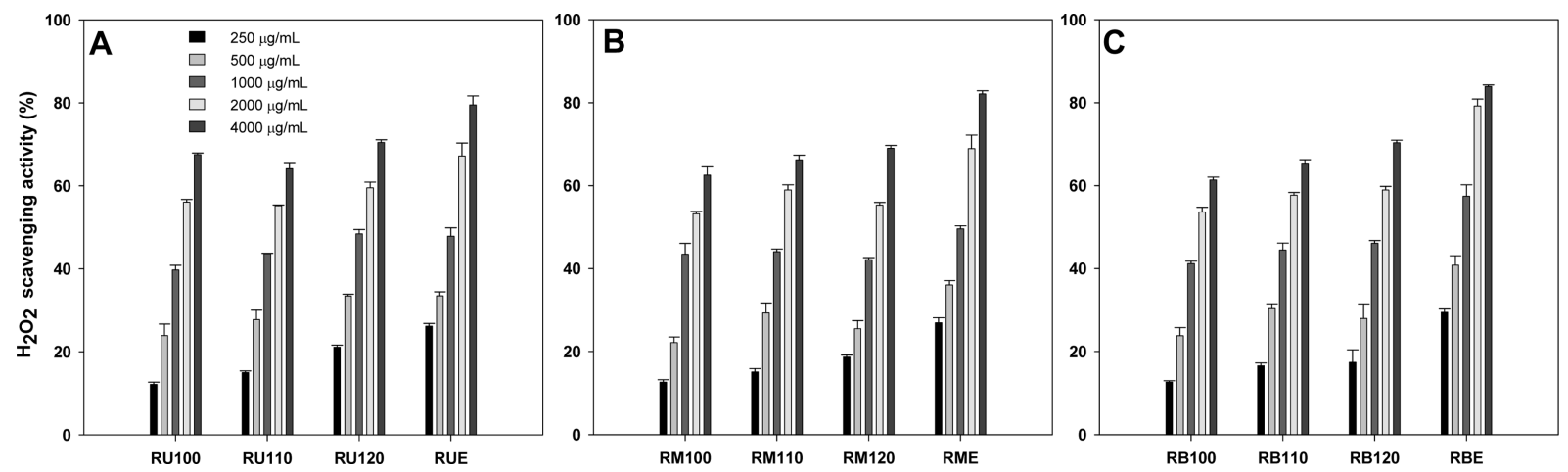

Fig. 3. Hydrogen peroxide scavenging activities of Russian deer velvet antler extracts. (A), Upper part extracts with hot water at $100^{\circ} \mathrm{C}, 110^{\circ} \mathrm{C}$, and $120^{\circ} \mathrm{C}$ and $70 \%$ ethanol; (B), Middle part extracts with hot water at $100^{\circ} \mathrm{C}, 110^{\circ} \mathrm{C}$, and $120^{\circ} \mathrm{C}$ and $70 \%$ ethanol; (C), Base part extracts with hot water at $100^{\circ} \mathrm{C}, 110^{\circ} \mathrm{C}$, and $120^{\circ} \mathrm{C}$ and $70 \%$ ethanol. Results are presented as means $\pm \mathrm{SE}$ of three determinations.

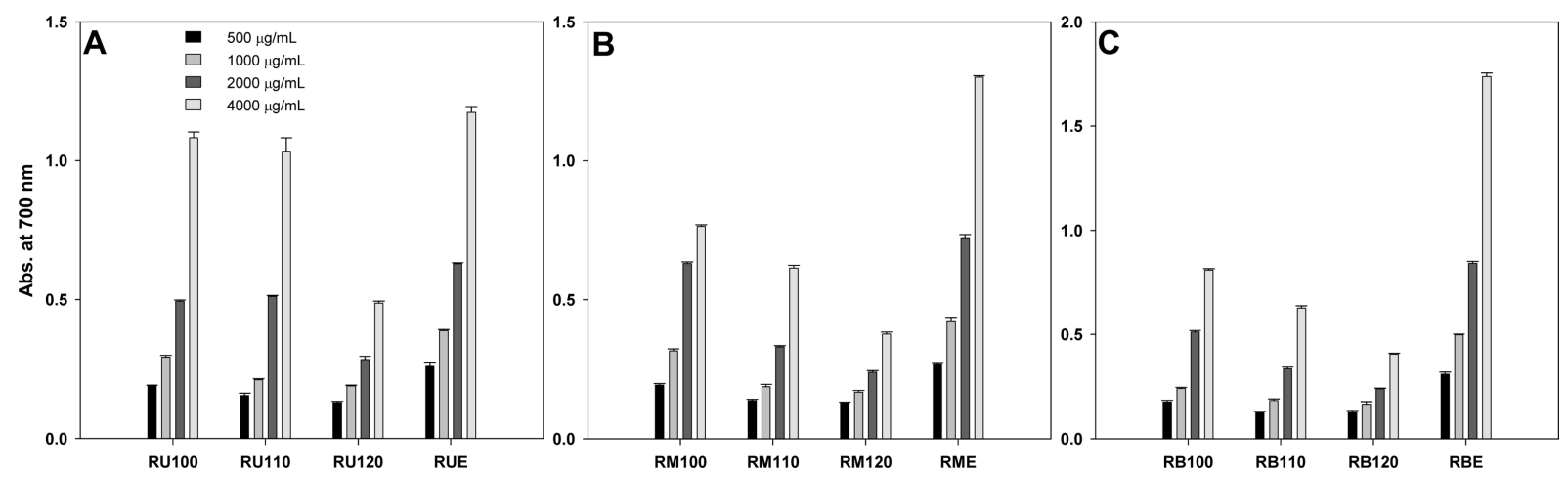

Fig. 4. Reducing power of Russian deer velvet antler extracts. (A), Upper part extracts with hot water at $100^{\circ} \mathrm{C}, 110^{\circ} \mathrm{C}$, and $120^{\circ} \mathrm{C}$ and $70 \%$ ethanol; (B), Middle part extracts with hot water at $100^{\circ} \mathrm{C}, 110^{\circ} \mathrm{C}$, and $120^{\circ} \mathrm{C}$ and $70 \%$ ethanol; (C), Base part extracts with hot water at $100^{\circ} \mathrm{C}, 110^{\circ} \mathrm{C}$, and $120^{\circ} \mathrm{C}$ and $70 \%$ ethanol. Results are presented as means $\pm \mathrm{SE}$ of three determinations.
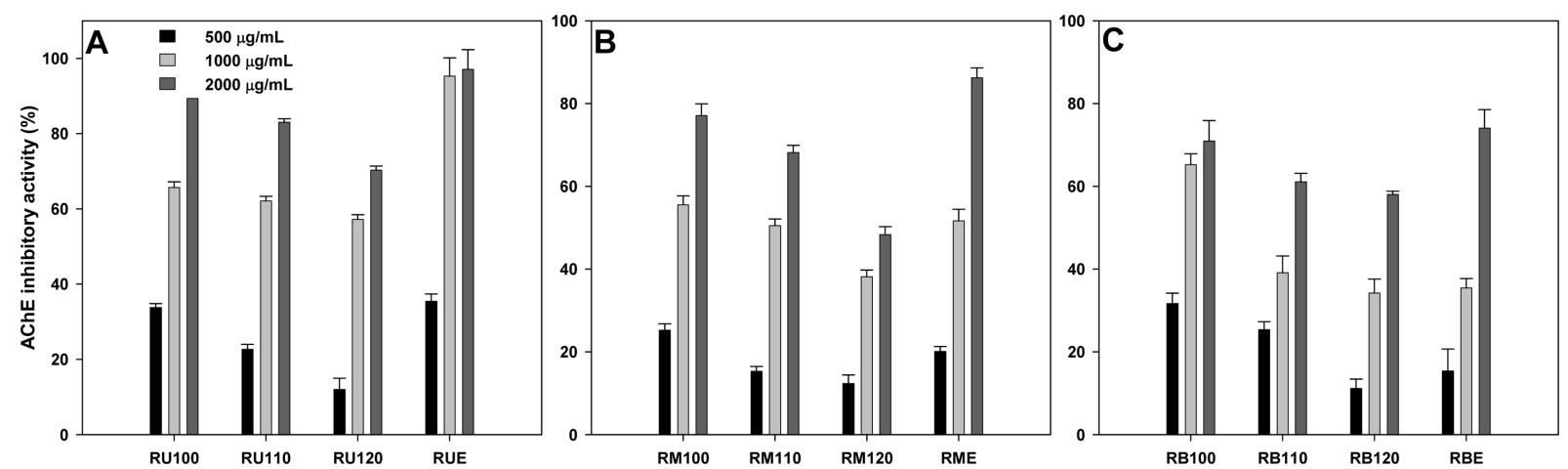

Fig. 5. Acetylcholinesterase inhibitory activity of Russian deer velvet antler extracts. (A), Upper part extracts with hot water at $100^{\circ} \mathrm{C}, 110^{\circ} \mathrm{C}$, and $120^{\circ} \mathrm{C}$ and $70 \%$ ethanol; (B), Middle part extracts with hot water at $100^{\circ} \mathrm{C}, 110^{\circ} \mathrm{C}$, and $120^{\circ} \mathrm{C}$ and $70 \%$ ethanol; (C), Base part extracts with hot water at $100^{\circ} \mathrm{C}, 110^{\circ} \mathrm{C}$ and $120^{\circ} \mathrm{C}$ and $70 \%$ ethanol. Results are presented as means $\pm \mathrm{SE}$ of three determinations.

various diseases such as anemia, arthritis, hypercholesterolemia, and cancer or to promote health as a traditional oriental tonic (Fennessy, 1991; Kang et al., 2006; Sunwoo et al., 1995). Therefore, antler parts are a useful ingredient for developing new food products and/or nutraceuticals capable of modulating the physiology of human's body and protecting humman against diseases. However, the upper part normally includes the tip part since the tip part is of very small quantity compared to other parts. In Korea, consumers generally believe that the 
upper parts of antler root are the most effective for treating various diseases. This stimulated our curiosity to evaluate the antioxidant effects of antler root in different in vitro model systems using artificial induction of free radicals or ROS and to determine its biochemical contents of uronic acid, sulfated-GAGs, and sialic acid.

In Korea, velvet antler is generally subjected to extraction as a traditional medical practice $\left(1 \mathrm{~atm}, 100^{\circ} \mathrm{C}\right)$. To determine whether or not this practice is sufficient for the complete extraction of functional components from velvet antler, we used the residue from the second and third extraction process described in the Materials and Methods part. We also investigated the levels of biochemical components as well as the antioxidant activities of velvet antler extracts using different extraction solvents. For this, extraction of velvet antler was performed using an autoclave machine at different temperatures.

Table 1 displays the biochemical composition of the velvet antler extracts. Based on these results, all biochemical components determined in this study were not completely extracted at $100^{\circ} \mathrm{C}$. Considerable amounts of uronic acid and sulfated-GAGs were detected at high temperature compared to extracts at $100^{\circ} \mathrm{C}$. Furthermore, high temperature was needed to extract sialic acid. These results indicate that traditional medical practice could not fully extract the functional components. The uronic acid, sulfated-GAGs, and sialic acid contents of the ethanol extracts showed different patterns compared to the hot water extracts. Ethanol was more appropriate for extraction of uronic acids, as its content was equal to the sum of the hot water extracts. However, sulfated-GAGs and silaic acid were not extracted by ethanol.

To verify the beneficial bioactivity of the velvet antler extracts, we tried to examine the antioxidant activities in vitro using several model systems. Fig. 1 shows the DPPH scavenging activities of the extracts. All extracts, including the upper, middle, and base parts, exhibited good scavenging activity, and the activity was dependent on the extract temperature. It is well known that DPPH is a stable radical and accepts an electron and/or hydrogen radical from donors to become a stable diamagnetic molecule. Therefore, the extracts of velvet antler could have provided an electron and/or hydrogen radical. The RU100, RM100, and RB100 extracts at $100^{\circ} \mathrm{C}$ showed good scavenging ability compared to those of the RU110, RM110, and RB110 and RU120, RM120, and RB120 extracts. This result indicates that a considerable amount of antioxidant compounds were extracted at $100^{\circ} \mathrm{C}$, but also a high amount of antioxidant compounds existed in the residue.
Therefore, the optimal extraction conditions of velvet antler include high temperature and pressure. Ethanol extracts also exhibited lower levels of DPPH scavenging activity than that of the hot water extracts. However, the activities of the parts exhibited no significant difference. Hydrogen peroxide is a reactive non-radical and an important compound as it can penetrate biological membranes. Hydrogen peroxide can also be converted into more reactive species, such as singlet oxygen and hydroxyl radicals, thereby causing lipid peroxidation or toxicity to cells. Therefore, it is important to scavenge hydrogen peroxide to decrease the level of prooxidants. As shown in Fig. 2, velvet antler extracts showed higher hydrogen peroxide scavenging capacity, and the activities of all the extracts were similar. This result also indicates that considerable antioxidant content existed in the residue. Measurement of reducing power was carried out to evaluate the content reductones, which are capable of reducing ferric (III) iron to ferrous (II) in a redox-linked colorimetric reaction, by single electron transfer from the antioxidant components. As shown in Fig. 3, velvet antler extracts exhibited strong reducing power. Among the hot water extracts, reducing power decreased with increasing extraction temperature, whereas the $70 \%$ ethanol extracts (RUE, RME, and RBE) exhibited higher reducing power than those of the hot water extracts.

We also carried out anti-AChE activity assay. The efficacy of cholinergic therapies in treating $\mathrm{AD}$ supports the cholinergic hypothesis and validates this neurotransmitter system as a therapeutic target (Andreani et al., 2008). Therefore, AChE inhibitors currently being used in clinical trials along with some chemically synthesized inhibitors appear to give rise to severe side effects such as nausea, vomiting, bradycardia, anorexia, and sweating (Giacobini, 2004; Jia et al., 2009). Therefore, naturally occurring AChE inhibitors without side effects have earned much attention for treatment of $\mathrm{AD}$. Velvet antler is a naturally occurring product and has long been used as a medicinal treatment. In this study, we provided evidence that velvet antler extracts showed anti-AChE activity with different levels of inhibition activity using different extraction methods.

From the present results, the extraction of biochemical components from Russian deer velvet antler was dependent on each biochemical component. For the effective extraction, both water with different temperature and ethanol extraction methods may be needed to combine to extract the biochemical components including uronic acid, sulfated-GAGs, and sialic acid. In addition, all 
extracts showed good antioxidant and anti-AChE activity, however, in vivo experiments are needed to clarify its effectiveness.

\section{Acknowledgment}

This work was financially supported by AcademiaIndustry Cooperation Division Support Project in 2007 funded by SMBA, Republic of Korea.

\section{References}

1. Andreani, A., Burnelli, S., Granaiola, M., Guardigli, M., Leoni, A., Locatelli, A., Morigi, R., Rambaldi, M., Rizzoli, M., Varoli, L., and Roda, A. (2008) Chemiluminescent highthroughput microassay applied to imidazo[2,1-b]thiazole derivatives as potential acetylcholinesterase and butyrylcholinesterase inhibitors. Eur. J. Med. Chem. 43, 657-661

2. Blois, M. S. (1958) Antioxidant determination by the use of a stable free radical. Nature 181, 1533-1535.

3. Butterfield, D. A., Castenga, A., Pocernich, C. B., Drake, J., Scapagnini, G., and Calabrese, V. (2002) Nutritional approaches to combat oxidative stress in Alzheimer's diseases. J. Nutr. Biochem. 13, 444-461.

4. Cesaretti, M., Luppi, E., Maccari, F., and Volpi, N. (2003) A 96-well assay for uronic acid carbazole reaction. Carbohydr. Polym. 54, 59-61.

5. Ellman, G. L., Courtney, D., Andres, K. D. V., and Featherstone, R. M. (1961) A new and rapid colorimetric determination of acetylcholinesterase activity. Biochem. Pharmacol. 7, 88-95.

6. Farndale, R. W., Buttle, D. J., and Barrett, A. J. (1986) Improved quantitation and discrimination of sulphated glycosaminoglycans by use of dimethylmethylene blue. Biochem. Biophy. Acta-General Subjects 883, 173-177.

7. Fennessay, P. F. (1991) Velvet antler: the product and pharmacology. Proceed. Deer Course for Veterinarians, No. 8; New Zealand, pp. 169-180.

8. Giacobini, E. (2004) Cholinesterase inhibitors: new roles and therapeutic alternatives. Pharmacol. Res. 50, 433-440.

9. Je, J. Y., Park P. J., Kim, E. K., Kim, H. A., Lim, D. H., Jeon, B. T., and Ahn, C. B. (2010) Composition of Biologically Active Substances and Antioxidant Activity of New Zealand Deer Velvet Antler Extracts. Korean J. Food Sci. Ani. Resour. 30, 20-27.

10. Jia, P., Sheng, R., Zhang, J., Fang, L., He, Q., Yang, B., and $\mathrm{Hu}$, Y. (2009) Design, synthesis and evaluation of galanthamine derivatives as acetylcholinesterase inhibitors. Eur. $J$. Med. Chem. 44, 772-784.

11. Kang, S. K., Kim, K. S., Kim, S. I., Chung, K. H., Lee, I. S., and Kim, S. H. (2006) Immunosuppressive activity of deer velvet antler extracts of Cervus korean TEMMINCK var. mantchuricus Swinhoe, on type II collagen-induced arthritis. In Vitro Cell. Dev. Biol. Animal 42, 100-107.

12. Kim, Y. C. (1994) Pharmacological properties of Cervi cornu. Proceed. Int. Sym. On Cervi Parvum Cornu, Korean Soc. Pharmacogn., Seoul, Korea.

13. Müller, H. E. (1985) Detection of hydrogen peroxide produced by microorganism on ABTS-peroxidase medium. Zentralbl Bakteriol. Microbiol. Hyg. 259, 151-158.

14. Oyaizu, M. (1986) Studies on products of browning reaction: antioxidative activities of products of browning reaction prepared from glucosamine. Jpn. J. Nutr. 44, 307-315.

15. Paroli, E., Antonilli, L., and Biffoni, M. (1991) A pharmacological approach to glycosaminoglycans. Drugs Exp. Clin. Res. 17, 9-20.

16. Pryor, W. A. and Ann, N. Y. (1982) Free radical biology: xenobiotics, cancer, and aging. Acad. Sci. 393, 1-22.

17. Sunwoo, H. H., Nakano, T., Hudson, R. J., and Sim, J. S. (1995) Chemical composition of antlers from Wapiti (Cervus elaphus). J. Agri. Food Chem. 43, 2846-2849.

18. Sunwoo, H. H., Nakano, T., and Sim, J. S. (1997) Effect of water-soluble extract from antler of wapiti (Cervus elaphus) on the growth of fibroblasts. Can. J. Anim. Sci. 77, 343-345.

19. Suttie, J. M., Fennessy, P. F., Haines, S. R., Sadighi, M., Kerr, D. R., and Isaacs, C. (1994) The New Zealand velvet antler industry: Background and research findings. Proceed. Int. Sym. On Cervi Parvum Cornu, Korean Soc. Pharmacogn., Seoul, Korea.

20. Takikawa, K., Kokuba, N., Kajihara, M., Dohi, M., and Tahara, N. (1972) Studies of experimental whiplash injury (III)- changes in enzyme activity of cervical cords and effect of Pantui extracts, Pantocrin as a remedy. Folia Pharmacologica Japonica 68, 489-493.

21. Wang, B. X., Zhao, X. H., Qi, S. B., Kaneko, S., Hattori, M., Namba, T., and Nomura, Y. (1988a) Effects of repeated administration of deer antler (Rokujo) extract on biochemical changes related to aging in senescence-accelerated mice. Chem. Pharm. Bull. 36, 2587-2592.

22. Wang, B. X., Zhao, X. H., Yang, X. W., Kaneko, S., Hattori, M., Namba, T., and Nomura, Y. (1988b) Inhibition of lipid peroxidation of deer antler (Rokujo) extract in vivo and in vitro. J. Med. Pharm. Soc. Wakan Yaku 5, 123-128.

23. Warren, L. (1959) The thiobarbituric acid assay of sialic acids. J. Biol. Chem. 234, 1971-1975.

24. Zhang, Z. Q., Wang, B. X., Zhou, H. O., Wang, Y., and Zhang, H. (1992) Purification and partial characterization of anti-inflammatory peptide from pilose antler of Cervus Nippon Temminck. Yaoxue Xuebao 27, 321-324.

(Received 2011.2.7/Revised 2011.4.5/Accepted 2011.4.7) 